\title{
Cytohistological correlation in salivary gland, in the Hospital General de México, from 2009 to 2016
}

\author{
Omar Choreño-García* and Susana Córdova-Ramírez \\ Unidad de Citopatología, Hospital General de México: "Dr. Eduardo Liceaga”, Mexico City, Mexico
}

\begin{abstract}
Background: Several diseases can produce enlargement of salivary glands and the fine-needle aspiration biopsy (FNAB) helps establishing a diagnosis. Methods: A retrospective study was conducted, in which the interpretation of 383 of salivary gland FNAB studies was evaluated, with the histopathological findings of the follow-up biopsies performed from 2009 to 2016, at Hospital General de México "Dr. Eduardo Liceaga." The presence or absence of malignant neoplasm in the surgical specimens (gold standard) was considered as a positivity parameter. Results: To detect malignancy, a sensitivity ratio of $62.5 \%$, specificity of $98 \%$, positive predictive value of $90.9 \%$, and negative predictive value of $90.1 \%$ were obtained with diagnostic accuracy of $90.2 \%$ of the salivary gland FNAB. Adenoid cystic carcinoma was the most frequent cytological interpretation of a specific malignant neoplasm and pleomorphic adenoma of a benign neoplasm. Conclusions: Salivary gland FNAB provides accurate and useful information about the type of pathology, which allows for better management of patients. Our results are similar to the parameters established in literature.
\end{abstract}

Key words: Fine-needle aspiration biopsy. Salivary gland. Biopsy correlation.

\section{Background}

One of the main objectives of fine-needle aspiration biopsy (FNAB) of the salivary gland is the preliminary evaluation of lesions in these organs, which together with the clinical and image information, helps determining therapeutic decisions: Is surgery indicated in this case or only follow-up is required? How urgent and extensive should the surgery be? ${ }^{1-3}$.

There are studies that showed that salivary gland FNAB decreases the number of surgical procedures; thus, it represents a very useful study due to its low cost and effectiveness ${ }^{4}$.

There have been few recent international studies in the United States or Europe, in which new modalities of imaging studies allow for a more accurate pre-operative diagnosis of salivary gland lesions ${ }^{5,6}$, in which the cytohistological correlation of salivary gland FNAB is evaluated.

It should be mentioned that classification and reporting systems regarding salivary gland cytology findings have been proposed recently. These systems are similar to those used in other organs to standardize FNAB results ${ }^{7,8}$.

There are several recent reports of studies from Asian and Latin American countries where this technique is still used and confirms that salivary gland FNAB is a very useful study due to its sensitivity and specificity value ${ }^{9-12}$.

In Mexico, there are no recent studies published in scientific journals about this salivary gland FNAB
Correspondence:

*Omar Choreño-García

E-mail: omarchg88@ hotmail.com

under the CC BY-NC-ND license (http://creativecommons.org/licenses/by-nc-nd/4.0/). 
aspect. In a study performed in 1999 at Hospital General "Dr. Manuel Gea González," information obtained therein was similar to that reported in the specialized literature and in hospital centers of other countries ${ }^{13}$.

Salivary gland lesions are superficial and of considerable size most of the time, and represent an important percentage of head and neck pathologies ${ }^{14}$. Hence, FNAB represents a useful study in the diagnosis and management of these clinical conditions, especially when taking into account the considerable number of entities that affect the salivary gland ${ }^{15}$.

The importance of cytohistological correlation at cytopathology laboratories is well established, for its continuous improvement ${ }^{16}$. It is equally important that the information obtained be published so that the quality of cytology laboratories can keep being verified and evidenced, mainly of our hospital which, due to the number and variety of studies it receives, is a cytopathology specialized center. Moreover, more recent and relevant information about the usefulness of salivary gland FNAB can be reported.

\section{Materials and methods}

A descriptive, retrospective, cross-sectional, and observational study of the cytological studies of salivary gland lesions was conducted at the Cytopathology Unit of the General Hospital of Mexico (Hospital General de México) from January 2009 to May 2016.

Information was obtained from the cytopathology unit database of the studies referred to as salivary gland lesions with proper samples for diagnosis, which generated 383 cases (Fig. 1). For these cases, the search was aimed at cases that had been the subject of histopathological study at the surgical pathology system of the anatomical pathology service, selecting those in which the salivary gland lesion had undergone biopsy or subsequent surgical resection, to evaluate the cytohistological correlation and statistical analysis of obtained data.

To assess sensitivity, specificity, and positive and negative predictive value, the presence or absence of malignancy in surgical specimens (gold standard) was deemed a positivity parameter.

\section{Results}

The 383 cytopathological studies were diagnosed as follows (according to the classification system of the unit): salivary gland without alterations, acute sialadenitis, chronic sialadenitis, granulomatous sialadenitis,

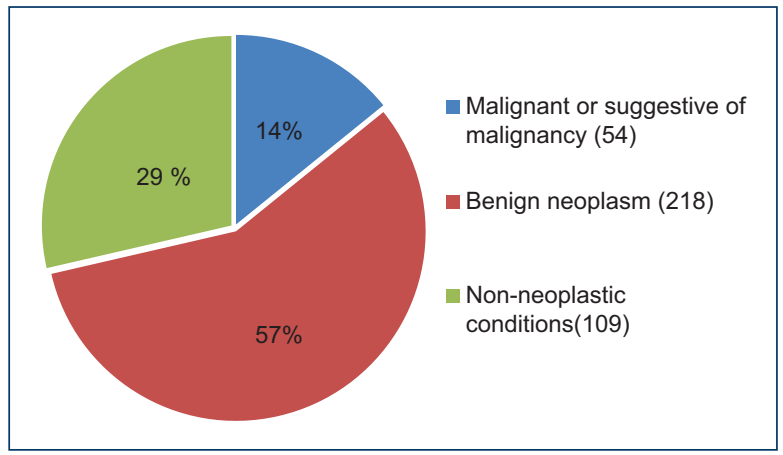

Figure 1. Salivary gland fine-needle aspiration biopsy (total=383).

benign tumor, Warthin's tumor, mixed salivary gland tumor, atypical cells, suspicious for malignancy, positive for malignant cells, carcinoma ex pleomorphic adenoma, adenoid cystic carcinoma, and mucoepidermoid carcinoma; it is important to mention that three main groups were classified for searching these studies: malignant neoplasm or suggestive of malignancy (atypical cells - although this interpretation in most systems carries a greater possibility of a benign condition, it represents a certain risk of malignancy ${ }^{7,8}$, suspicious for malignancy, positive for malignant cells, carcinoma ex pleomorphic adenoma, adenoid cystic carcinoma, and mucoepidermoid carcinoma), benign neoplasm (benign tumor, Warthin's tumor, and mixed salivary gland tumor), and non-neoplastic lesions (salivary gland without alterations, acute sialadenitis, chronic sialadenitis, and granulomatous sialadenitis).

Only 216 cases had histopathological study to perform the correlation. In the malignant neoplasm group or suggestive of it, it was found that of 56 salivary gland FNABs interpreted in this way, 33 cases had histopathological study (Table 1). The average age in this category was 60.6 years (range of 21-89). As for gender, there were 20 cases in women (60\%) and 13 in men (40\%).

Regarding the cases interpreted as positive for malignant cells, in eight of them, interpretation was added by the probable histological type corresponding to the neoplasm: three as malignant myoepithelial neoplasms, one compatible with acinar cell carcinoma, one compatible with ductal carcinoma, one as probably neuroendocrine carcinoma, and two cases compatible with lymphoproliferative neoplasm.

Regarding the benign neoplasm group, 219 FNAB studies were interpreted in this way, of which 144 cases had been subjected to histopathological study (Table 2). As for demographic data (age and sex), the majority 
Table 1. Malignant cases or suggestive of malignancy

\begin{tabular}{|l|c|c|c|}
\hline & $\mathbf{n}(\%)$ & True positives & False positives \\
\hline Adenoid cystic carcinoma & $7(21)$ & 7 & 0 \\
\hline Mucoepidermoid carcinoma & $5(15)$ & 4 & 1 (chronic granulomatous sialadenitis) \\
\hline Carcinoma ex pleomorphic adenoma & $1(3)$ & 1 & 1 (AP) \\
\hline Positive for malignant cells & $17(52)$ & 16 & 0 \\
\hline Suspected malignancy & $2(6)$ & 2 & 1 (necrotic tissue and inflammatory infiltrate) \\
\hline Atypical cells & $1(3)$ & 0 & 3 \\
\hline Total & $33(100)$ & 30 & .
\end{tabular}

Table 2. Benign neoplasm cases

\begin{tabular}{|l|c|c|c|}
\hline & $\mathbf{n}(\%)$ & True negatives & False negatives \\
\hline Pleomorphic adenoma (benign mixed tumor) & $128(89)$ & 115 (3 of non-neoplastic processes*) & $\begin{array}{c}13 \text { (4 CXPA, 4 ACC, 2 MEC, 1 PLGA, } \\
1 \text { SDC, } 1 \text { sarcoma**) }\end{array}$ \\
\hline Warthin's tumor & $9(6)$ & $8(7 \mathrm{WT}, 1 \mathrm{BLEL})$ & 1 (ACC) \\
\hline Benign tumor & $7(5)$ & $\begin{array}{c}6(2 \mathrm{PA}, 1 \mathrm{BCA}, 3 \text { of non-neoplastic } \\
\text { processes }\end{array}$ & 1 (MMT) \\
\hline Total & $144(100)$ & 129 & 15 \\
\hline
\end{tabular}

CXPA: carcinoma ex pleomorphic adenoma; ACC: adenoid cystic carcinoma; MEC: mucoepidermoid carcinoma; PLGA: polymorphous low-grade adenocarcinoma;

SDC: salivary duct carcinoma; ACC: acinar cell carcinoma; WT: Warthin's tumor; BLEL: benign lymphoepithelial lesion; PA: pleomorphic adenoma; BCA: basal cell adenoma; MMT: malignant myoepithelial tumor; ${ }^{*} 1$ case of sialolithiasis with chronic sialadenitis and 2 cases of chronic granulomatous inflammation, one in lymph node,

**Low-grade sarcoma, ${ }^{* * *} 1$ parotid abscess, 1 case of parotid gland oncocytosis and 1 lymphoepithelial cyst in lymph nodes.

Table 3. Cases of non-neoplastic processes

\begin{tabular}{|c|c|c|c|}
\hline & n (\%) & True negatives & False negatives \\
\hline Acute sialadenitis (abscess) & $3(8)$ & 3 (2 chronic sialadenitis, 1 WT) & 0 \\
\hline Chronic sialadenitis & $11(28)$ & $\begin{array}{c}11 \text { (6 chronic sialadenitis, } 2 \text { with fatty infiltration, } 1 \text { without } \\
\text { histological alterations, } 2 \text { AP) }\end{array}$ & 0 \\
\hline Granulomatous sialadenitis & 1 (3) & 0 & 1 (DLBCL) \\
\hline Cystic lesion & $13(33)$ & $\begin{array}{c}13 \text { (3 WT, } 3 \text { chronic sialadenitis, } 2 \text { PA, } 2 \text { BCC, } 1 \text { TDC, } 1 \text { GCT, } 1 \\
\text { cyst capsule) }\end{array}$ & 0 \\
\hline Salivary gland without alterations & $9(23)$ & 7 (5 without alterations, 2 AP) & $2(1 \mathrm{ACC}$ y $1 \mathrm{ACC})$ \\
\hline Lymphoid tissue & $2(5)$ & 2 (1 chronic sialadenitis, 1 with fatty infiltration*) & 0 \\
\hline Total & $39(100)$ & 36 & 3 \\
\hline
\end{tabular}

WT: Warthin's tumor; PA: pleomorphic adenoma; DLBCL: diffuse large B-cell lymphoma; BCC: branchial cleft cyst; TDC: thyroglossal duct cyst; GCT: granular cell tumor; ACC: acinar cell carcinoma; ACC: adenoid cystic carcinoma; *It was accompanied by granulomatous lymphadenitis.

$(67.5 \%)$ were women and the average age was 42.2 years (range of 16-88).

One hundred and nine cytological interpretations were issued regarding the diagnoses considered as non-neoplastic conditions. Only 39 of them had subsequent biopsies (Table 3); of these cases, 24 corresponded to women (61\%) and 15 to men (39\%), most patients were in their fifties (average of 45.8 years, range of 22-70).

We found 30 true positive cases (malignant cytology and surgical specimen), 165 true negatives (benign or non-neoplastic cytology and histopathology), 3 false 
Table 4. Cytological and histopathological diagnoses

\begin{tabular}{|l|c|c|c|}
\hline \multirow{2}{*}{ Fine-needle aspiration biopsy diagnosis } & \multicolumn{2}{|c|}{ Histopathological diagnosis } & \multirow{2}{*}{ Total } \\
\cline { 2 - 4 } & Malignant neoplasm & Benign neoplasm or non-neoplastic process & 33 \\
\hline Malignant neoplasm & $30(\mathrm{VP})$ & 3 (FP) & 183 \\
\hline Benign neoplasm or non-neoplastic process & $18(\mathrm{FN})$ & 165 (VN) & 216 \\
\hline Total & 48 & 168 & 2 \\
\hline
\end{tabular}

positives (malignant cytology and benign or non-neoplastic histopathological study), and 18 false negatives (benign or non-neoplastic cytology and malignant biopsy) (Table 4).

Thus, we have a sensitivity ratio of $62.5 \%$, specificity of $98 \%$, positive predictive value of $90.9 \%$, negative predictive value of $90.1 \%$, and diagnostic accuracy of $90.2 \%$.

\section{Discussion}

A high number of cytologic evaluations of salivary gland lesions are carried out at the Cytopathology Laboratory of the General Hospital of Mexico, in direct evaluation as well as material sent to the laboratory. Between 2009 and 2013, more than 500 samples with these characteristics have been received. However, there is no recent published information from this hospital or from another hospital in the country, about the diagnostic accuracy of this type of studies.

One of the main drawbacks of salivary gland FNAB is the percentage of inadequate punctures. In our hospital, these inadequate punctures correspond to $31 \%$ (172 studies in the period under study) which is much higher than reported in literature ${ }^{17}$. The reasons behind this could be that most biopsies are not examined by a cytopathologist at the place where the puncture is performed, to assess their adequacy.

In terms of gender, there is a predominance of females for different types of lesions in the three initially divided study groups. For non-neoplastic and benign neoplastic lesions, the average age was 50 years+, and for malignant neoplasms, the average age was nearly 20 years older, the latter differing from that reported in literature ${ }^{18}$. The cytological material sent to the laboratory seldom refers to salivary gland punctures. However, in those materials where this information appears, the majority correspond to parotid gland lesions.

For malignant lesions, there was a good correlation in the studies interpreted as malignant cells, in which a diagnostic possibility was added where it could be determined that one of them corresponded to neuroendocrine carcinoma. It is also worth noting that the interpretation of a more frequent specific malignant neoplasm corresponded to adenoid cystic carcinoma (Fig. 2). In addition, there were no other false positives.

Likewise, regarding the cases, in which a diagnostic probability was given, three interpretations of lymphoproliferative processes were issued, which show a broadly commented aspect in literature (also observed in the other groups of lesions) ${ }^{19,20}$. Although punctures are performed in many cases due to a suspicious lesion that may be rooted in the salivary gland, such a lesion generally corresponds to another organ, the lymph node. Furthermore, two of the cases that were diagnosed by cytology as malignant neoplasms of the salivary gland, on examination of the surgical specimens, it was found that one of them corresponded to lymph nodes with metastases from carcinomas of these sites and another to an adenoid cystic carcinoma in soft tissues of the neck.

There were only three false positives, the error of which, in two of them, was due to small biopsies in subsequent surgical studies (one in which only necrotic tissue and inflammation were examined and another in which it was diagnosed as a pleomorphic adenoma, but it was specified that the biopsy was small). Due to sampling problems, this time related to FNAB cases, some cases interpreted as chronic sialadenitis or salivary gland without alterations corresponded to both benign and malignant neoplasms in the surgical specimens.

However, a case interpreted as mucoepidermoid carcinoma stands out, which corresponded to chronic granulomatous inflammation; and in the category of non-neoplastic conditions, a false negative was presented with an FNAB wrongly interpreted as granulomatous sialadenitis that in the histopathological study was diagnosed as diffuse large B-cell lymphoma. In other studies, regarding the cytology of other organs, this type of problem has been reported for the 


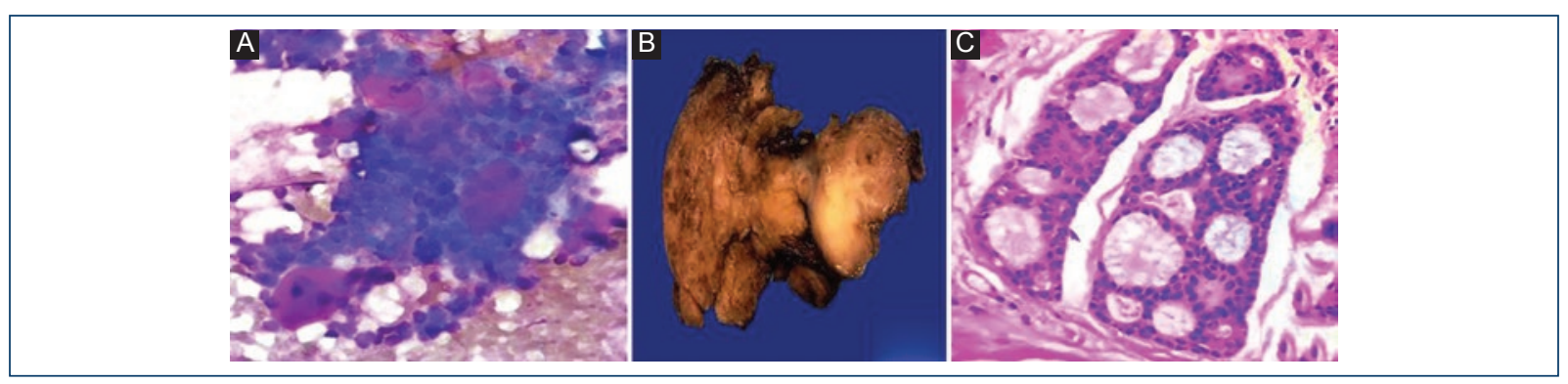

Figure 2. Adenoid cystic carcinoma. A: Groups of cells with basaloid appearance, without atypia, associated with a matrix in an ovoid globular shape. B: Poorly delimited and invasive lesion. C: Cribriform growth pattern.

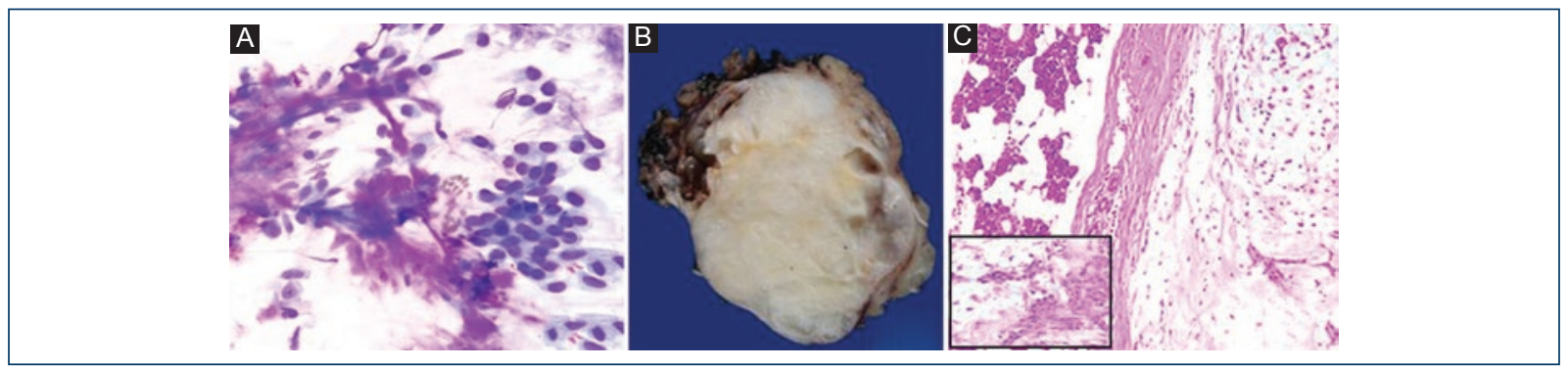

Figure 3. Pleomorphic adenoma. A: Tapered cells associated with matrix of fibrillary aspect. B: Lesion of expansive edges, with compression of the residual parenchyma. C: Encapsulated lesion, with abundant chondromyxoid matrix and benign-looking myoepithelial cells (inset).

interpretation of granulomatous inflammation, considering it a cause of false positives and negatives ${ }^{21,22}$.

In the group of benign neoplasms, the most frequent type, as mentioned in literature, corresponds to the pleomorphic adenoma (Fig. 3), but for this interpretation, there was the highest number of false negatives for malignancy. In some cases, the distinction was complicated by limitations inherent to cytology, in which the growth pattern could not be assessed, one of the most useful criteria for distinguishing it from carcinoma ex pleomorphic adenoma ${ }^{18}$. In addition, the pleomorphic adenoma component can sometimes hide the presence of neoplastic cells with malignant characteristics ${ }^{23}$.

The number of cases of adenoid cystic carcinomas was equal to that of carcinomas ex pleomorphic adenomas, which were interpreted as pleomorphic adenoma in the cytological material, which shows us why these neoplasms are considered matrix-containing tumors in salivary gland cytology texts regarding their differential diagnosis ${ }^{24}$. In a study that assessed the accuracy and false-negative rate of FNAB in cases of adenoid cystic carcinoma, it was found that the most common diagnostic failure is to differentiate this neoplasm from pleomorphic adenoma ${ }^{25}$.

For Warthin's tumor (lymphomatous papillary cystadenoma or adenolymphoma), there was only one false negative that corresponded to a case of acinar cell carcinoma. This situation has been described because this latter neoplasm can have oncocytic appearance in cytology and it often lacks the morphological characteristics of malignancy ${ }^{26,27}$. It can even be misinterpreted as a normal salivary gland, as it happened during our review.

Moreover, regarding Warthin's tumor, situations similar to the previous one were found and described in literature, due to the characteristics of this neoplasm, such as cystic morphology (which means that in some FNAB studies, only detritus and/or an inflammatory background is observed), the lymphoid stroma, the oncocytic change, and the epidermoid metaplasia can be confused in cytology with different non-neoplastic conditions ${ }^{28,29}$ (one acute sialadenitis and three in which only a cystic lesion was established, in our review).

The sensitivity ratio, specificity, positive and negative predictive value, as well as diagnostic accuracy 
obtained herein are similar to that reported in the reviewed literature, with sensitivity as the lowest value parameter $(62.5 \%)$, equal to that reported in different studies and reviews, including information published in our country ${ }^{7-13}$, although it would be below the values reported in other reviews ${ }^{30}$.

\section{Conclusions}

The information obtained in this article supports FNAB usefulness for the initial study of salivary gland lesions, by providing information about the type of lesion, for both non-neoplastic processes and neoplasms, whether benign or malignant, which is of great value for the management and follow-up of patients. Regarding the cytohistopathological correlation, it is in accordance with expected parameters.

\section{Funding}

Existing resources at the hospital.

\section{Conflicts of interest}

It is hereby declared that there are no conflicts of interest in the publication and/or authorship of this article.

\section{Acknowledgments}

The authors would like to thank Dr. Susana Córdova Ramírez.

\section{Ethical disclosures}

Protection of human and animal subjects. The authors declare that no experiments were performed on humans or animals for this study.

Confidentiality of data. The authors declare that they have followed the protocols of their work center on the publication of patient data.

Right to privacy and informed consent. The authors declare that no patient data appear in this article.

\section{References}

1. Orell SR, Klijanienko J. Head and neck; salivary glands. In: orell and Sterret's Fine Needle Aspiration Cytology. $5^{\text {th }}$ ed. London: Churchill Livingstone Elsevier; 2012. p. 38-77.

2. Dey P. Salivary gland. In: diagnostic Cytology. New Delhi: Jaypee Brothers Medical Publishers; 2014. p. 298-318.

3. Kocjan G, Ramsay A, Beale T, O'Flynn P. Head and neck cancer in the UK: what is expected of cytopathology? Cytopathology. 2009;20:69-77.

4. Layfield LJ, Gopez E, Hirschowitz S. Cost efficiency analysis for fine-needle aspiration in the workup of parotid and submandibular gland nodules. Diagn Cytopathol. 2006;34:734-8.

5. Mihashi H, Kawahara A, Kage M, Kojiro M, Nakashima T, Umeno H, et al. Comparison of preoperative fine-needle aspiration cytology diagnosis and histopathological diagnosis of salivary gland tumors. Kurume Med J. 2006;53:23-7.

6. Muñoz C, Jiménez AC, Serrano RT, Mata RG, Molina PC, Muñoz IG, et al. Correlación citohistológica en tumores de la glándula parótida. Acta Otorrinolaringol Esp. 2010;61:184-8.

7. Wang H, Fundakowski C, Khurana JS, Jhala N. Fine-needle aspiration biopsy of salivary gland lesions. Arch Pathol Lab Med. 2015;139:1491-7.

8. Griffith CC, Pai RK, Schneider F, Duvvuri U, Ferris RL, Johnson JT, et al. Salivary gland tumor fine-needle aspiration cytology: a proposal for a risk stratification classification. Am J Clin Pathol. 2015;143:839-53.

9. Gupta R, Dewan D, Kumar D, Suri J. Fine-needle aspiration cytology (FNAC) of salivary gland lesions with histopathological correlation in a district hospital of Jammu región. Ind J Pathol Oncol. 2016;3:32-7.

10. Ashok Y, Kulkarni CV, Tiwari NP, Ravi J. Sonological, cytological, and histopathological correlation in parotid lesions: a 5-year experience. Int J Med Sci Public Health. 2015;4:709-12.

11. Khdhayer A, Al-Azawi MJ, Yasseen HA. Fine needle aspiration cytology in the diagnosis of head and neck masses. Eur Sci J. 2016;12:362-70.

12. Stramandinoli RT, Sassi LM, Pedruzzi PA, Ramos GH, Oliveira BV, Ogata DC, et al. Accuracy, sensitivity and specificity of fine needle aspiration biopsy in salivary gland tumours: a retrospective study. Med Oral Patol Oral Cir Bucal. 2010;15:e32-7.

13. Bross D, Urrutia RG, Gómez JR, Idi JS, Calleros HM, Martínez SP, et al. Correlación clínico-citológica e histopatológica de las neoplasias de las glándulas salivales. Med Asocc Med Hosp ABC. 1999;44:123-6.

14. Krane J, Faquin W. Salivary gland. In: cytology. Diagnostic Principles and Clinical Correlates. $4^{\text {th }}$ ed. Philadelphia, PA: Elsevier Saunders; 2014. p. 299-332.

15. Faquin W, Powers C. Introduction to FNA and Salivary Gland Neoplasia. Salivary Gland Cythopathology. $1^{\text {st }}$ ed. Boston: Springer; 2008. p. 1-17.

16. Bibbo M, Wilbur D. Diagnostic Quality Assurance in Cytopathology in Comprehensive Cytopathology. $3^{\text {rd }}$ ed. Philadelphia, PA: Saunders/Elsevier; 2008. p. 64-7.

17. Castro-Morillo A, Zamora-Díaz J, Castañeda A, Hernández-Fernández D. BAAF de Glándula Salival: Experiencia en el Hospital Faustino de Matanzas. Act Hisp Pat. 2006;1-15.

18. Everson JW, Auclair P, Gnepp DR, El-Nagggar AK. Tumours of the salivary glands: introduction. In: who Classification of Head and Neck tumours. $1^{\text {st }}$ ed. Lyon: IARC WHO; 2005. p. 212-5

19. Klijanienko J, Vielh P, Piekarsky JD. Imaging in Salivary Gland in Monographs in Clinical Cytology. Salivary Gland Tumours. Vol. 15. Basel: Karger; 2000. p. 7-8.

20. Kocjan G, Shah K. Salivary glands. In: diagnostic Cytopathology. $3^{\text {rd }}$ ed. London: Elsevier; 2010. p. 231-52.

21. Hafez NH, Fahim MI. Diagnostic accuracy and pitfalls of fine needle aspiration cytology and scrape cytology in oral cavity lesions. Russ Open Med J. 2014;3:405.

22. Auger M, Moriarty AT, Laucirica R, Souers R, Chmara BA, Fatheree LA, et al. Granulomatous inflammation-an underestimated cause of false-positive diagnoses in lung fine-needle aspirates: observations from the college of american pathologists nongynecologic cytopathology interlaboratory comparison program. Arch Pathol Lab Med. 2010;134:1793-6.

23. Elhosseiny A. Salivary glands. In: koos' Diagnostic Cytology and Histological Basis. $5^{\text {th }}$ ed. Philadelphia, PA: Lippincott Williams and Wilkins; 2006. p. 1231-61.

24. Faquin W, Powers C. Matrix-containing tumors: pleomorphic adenoma and adenoid cystic carcinoma. In: salivary Gland Cythopathology. $1^{\text {st }}$ ed. New York: Springer; 2008. p. 81-114

25. Tabatabai ZL, Auger M, Kurtycz DF, Laser A, Souers RJ, Laucirica R, et al. Performance characteristics of adenoid cystic carcinoma of the salivary glands in fine-needle aspirates: results from the college of American pathologists nongynecologic cytology program. Arch Pathol Lab Med. 2015;139:1525-30.

26. Al-Zaher N, Obeid A, Al-Salam S, Al-Kayyali BS. Acinic cell carcinoma of the salivary glands: a literature review. Hematol Oncol Stem Cell Ther. 2009;2:259-64.

27. Prieto-Rodríguez $M$, Artés-Martínez MJ, Navarro-Hervás $M$ Camañas-Sanz A, Vera-Sempere FJ. Cytological characteristics of acinic cell carcinoma (ACC) diagnosed by fine-needle aspiration biopsy (FNAB). A study of four cases. Med Oral Patol Oral Cir Bucal. 2005;10:103-8.

28. Parwani AV, Ali SZ. Diagnostic accuracy and pitfalls in fine-needle aspiration interpretation of warthin tumor. Cancer. 2003;99:166-71.

29. Garg D, Baja P, Sabharwal R, Gautam S. Fine needle aspiration cytology in warthin s tumor: a diagnosti tool. Diagn Pathol Open. 2015:1:102.

30. Hughes JH, Volk EE, Wilbur DC, Cytopathology Resource Committee, College of American Pathologists. Pitfalls in salivary gland fine-needle aspiration cytology: lessons from the college of American pathologists interlaboratory comparison program in nongynecologic cytology. Arch Pathol Lab Med. 2005;129:26-31 